\section{Epidemics caused by dead bodies: a disaster myth that does not want to die}

\section{Claude de Ville de Goyet ${ }^{1}$}

1 International Disaster Risk Management Consultant, Chevy Chase, Maryland, United States of America. Send correspondence to: Claude de Ville de Goyet, 5405 Center Street, Chevy Chase, Maryland 20815, United States of America; telephone: (301) 657-3898; e-mail: cdevill@attglobal.net.
Respect of the dead is a value deeply ingrained in all cultures and religions. However, it can be difficult to separate respect for the deceased from the deep fear of death itself that is common to all human beings. The little we know from many now-vanished civilizations is due to our findings in tombs and burial grounds. Rituals and practices may differ according to time, religion, or place: burial before sunset for Muslims, funeral after one night of prayer for Jews or before three days for Christians, the use of the white shroud in Oriental culture or the coffin in most of the Western world. However, under almost all circumstances, these traditions are strictly respected by believers and atheists alike.

Natural disasters cause large numbers of deaths in a short period of time, placing overwhelming stress on individuals and society and presenting health officials with an uncommon challenge of handling large numbers of cadavers. According to the International Federation of Red Cross and Red Crescent Societies (using data drawn from the EM-DAT database maintained by the Center for Research on the Epidemiology of Disasters (CRED), Belgium), in the ten-year period of 1993 through 2002, 531159 persons were killed by natural disasters, including 75391 in earthquakes and 93561 in floods (1). More recently, the earthquake that struck the city of Bam, Iran, on 26 December 2003 claimed 26271 lives in a matter of a few seconds (the initial estimate of over 43000 deaths has been reviewed and adjusted following a survey carried out by authorities).

In the Region of the Americas, mortality from natural disasters fluctuated widely over that same 1993-2002 period, from a low of 1820 in the year 2000 to highs of 21865 in 1998 (from Hurricane George and Hurricane Mitch and floods in Mexico) and 33989 in 1999 (most of them as a result of the floods in the north of Venezuela). A list of disasters in the Americas in recent decades that have caused over 1000 deaths is given in Table 1 .

In most of those sudden disasters - especially earthquakes - precipitous mass burials, incineration, or collective disposal of cadavers have been carried out under public and political pressure. During the 25 years I spent heading the Emergency Preparedness and Disaster Relief Program of the Pan American Health Organization, I could definitely see that even in the Americas there were few instances where the mass media did not publish alarming news on the risk of massive disease outbreaks after bodies were buried deep under the rubble or carried away by floods. For instance, following the Guatemala earthquake in 1976, legislators rushed into place emergency legislation mandating the immediate disposal of bodies. Since then, similar legislation has been considered by lawmakers in several other countries. With rash mass disposal of cadavers, identification of the deceased can seldom be completed. A notable exception was the considerable effort made by authorities in Mexico to help relatives identify unclaimed victims among the thousands of persons who were killed by the 1985 earthquake in Mexico City.

The Pan American Health Organization (PAHO) and the World Health Organization (WHO) have consistently advocated for the identification and proper burial of victims. In line with this policy, PAHO has discouraged emergency legislation on the expedited burial of victims from natural disasters and conflicts. Why should a health agency take a firm position concerning what is seen as merely a social, religious, or cultural issue that is beyond the scope of its expertise?

There are two compelling health reasons to explain this policy. First of all, mass burial has very serious health consequences. Identification of the body and the normal process of grieving are essential for prompt individual recovery from the severe stress caused by sudden natural disasters and personal losses. 
TABLE 1. Natural disasters in the Americas that have caused over 1000 deaths, $1970-2001^{a}$

\begin{tabular}{cccc}
\hline Year & Location & Type of disaster & Number killed \\
\hline 1970 & Peru & Earthquake & 73000 \\
1972 & Nicaragua & Earthquake & 10000 \\
1976 & Guatemala & Earthquake & 23000 \\
1979 & Dominican Republic & Hurricane & 1400 \\
1985 & Mexico & Earthquake & 8776 \\
1985 & Colombia & Volcanic eruption & 21800 \\
1987 & Ecuador & Earthquake & 4000 \\
1994 & Haiti & Storm & 1122 \\
1998 & Mexico & Flood & 1256 \\
1998 & Central America & Hurricane Mitch & 8607 \\
1999 & Colombia & Earthquake & 1186 \\
1999 & Venezuela & Flood & 30000 \\
2001 & El Salvador & Earthquake & 1159 \\
\hline a Most of the figures on the number of persons killed were preliminary estimates that officials \\
have never reviewed, so they are only indicative of the magnitude of the losses.
\end{tabular}

The inability to mourn a close relative, the lingering doubt on the whereabouts of the disappeared, and the legal limbo of the surviving spouse or child all contribute to the many potential mental health problems associated with disasters and the difficult rehabilitation process that follows. Denying the right to identify the deceased or suppressing the means to track the body for proper grieving adds to the mental health risks facing the affected population. The importance of grieving can be seen, for example, by the sustained determination of families of soldiers missing in action to formally identify their missing relatives. Almost 30 years after the Vietnam War ended, the costs and political difficulties involved have not discouraged persons in the United States from searching for evidence of their loved ones.

The second reason is that officials and the mass media justify expeditious measures for burial by the presumed risk that those bodies exposed to the environment would pose to public health. Common epidemiological sense and evidence had no place in the emergency decisions made in the Americas or more recently in the earthquakes in Gujarat, India, and Bam, Iran. An additional factor is the plain fact that most of the visible measures, such as superficial incineration or dusting with lime or "disinfectants," are unlikely to be of any effectiveness should the risk of disease transmission be real. Their value is only in the eyes of the public.

As shown with emergencies, unsubstantiated and uncontrolled fears may override basic values, including respect for the dead.

Public health concerns can be misrepresented in order to promote measures that may be harmful to the affected population. In such cases, health officials should work to see that the rights of relatives of the deceased are not overlooked in the midst of efforts to alleviate an unfounded public fear-a fear that is often also harbored by misinformed health professionals.

In this regard, the article (2) by Oliver Morgan in this issue of the Revista Panamericana de Salud Pública/Pan American Journal of Public Health makes a timely scientific contribution by clarifying an issue and informing the medical community. The author has objectively reviewed the available literature and experience and used an evidence-based approach to deal with this sometimes emotional subject. The article's systematic approach demystifies and rules out the risk of major catastrophic disease outbreaks as a consequence of decaying bodies remaining exposed after natural events or conflicts. The article also offers simple guidelines for those unfortunate workers having to deal in a safe but respectful manner with a large number of unidentifiable bodies. Too often the adoption of exotic precautions, such as masks and protective suits, accompanies a disregard for the basic hygiene and sanitation measures advocated in this article. 
The article emphasizes that survivors are a more likely source of disease outbreak. This point is well taken, and it calls attention to an effective strategy of disaster response: a strategy focused on providing primary health care for the victims and their families. Active surveillance and rapid restoration of normal public health services, including the provision of safe water and food, should be the priority.

Most interesting is the article's attempt to compare the occupational risk to health workers handling dead bodies in the aftermath of natural disasters with the potential exposure of persons who work in funeral homes. One may argue that the author's statement that "the risks are unlikely to be different" is perhaps overestimating the risk in natural disasters. If the occurrence of acute infections present in trauma victims is likely to be similar to that in the normal living population, that occurrence should be even higher in a "population" dying from disease, old age, and other causes, as seen by professional funeral workers.

It is hoped that this first comprehensive article on this important health subject will serve as a milestone for a change of opinion among disaster and health managers. Unfortunately, a single article may not be sufficient to dramatically change the existing practices in the Americas and elsewhere around the world. The problem is not anymore and perhaps has never been one of a lack of knowledge by epidemiologists and scientists. The issue is how those informed health professionals can and should stand up to the pressure of public opinion and protect the rights of the survivors when fears of the unknown are running rampant and officials seek an easy way to alleviate them.

The recent experience in Iran offers a particularly rich learning experience. In Bam, thousands of bodies were rapidly buried in common graves without ensuring a reasonable means of further identification and retrieval. The striking point is that at a disaster management workshop that I conducted in Tehran at the request of $\mathrm{WHO}$ and the Ministry of Health of Iran two months before that earthquake, the PAHO position against mass burial that I presented met with fierce debate, with provincial-level Iranian health authorities adamant that such a practice of mass burial would never take place in their cultural environment. However, field visits and interviews that I conducted in Bam after the earthquake on behalf of WHO revealed the intensity of the pressure on local health authorities to clear the city of bodies at all costs. Indeed, thousands of bodies were summarily buried with bulldozers, ruling out future identification and reburial. In my three decades of travel in the Region of the Americas, I have seen similar situations, showing how disaster-stricken communities and nations can be alike in their reactions to a catastrophe, regardless of their culture and religion.

So where should we go from here? The article in this issue is a critical step towards a solution. It is one key contribution to a strategy developed by PAHO and WHO that includes meetings of experts from around the Region of the Americas and the forthcoming publication by PAHO of comprehensive guidelines on the proper management of dead bodies in natural disasters. The guidelines will be published first in Spanish, with their posting on the PAHO Web site (http://www.paho.org/disasters/) expected in late 2004. Those steps alone will not be sufficient if health professionals are not ready to educate the public and the mass media. If we do not all undertake this task before disasters occur, we may continue to face pressures that few will be in a position to withstand. The psychological health of the victims will be a casualty, along with efforts and resources that could go to more needed public health measures.

\section{REFERENCES}

1. International Federation of Red Cross and Red Crescent Societies. World disasters report 2003. Geneva: IFRC; 2003.

2. Morgan O. Infectious disease risks from dead bodies following natural disasters. Rev Panam Salud Publica. 2004;15(5):307-12. 